\title{
A Case of Nonalcoholic Marchiafava- Bignami Disease with Left-Right Differential Agraphia of Chinese Characters
}

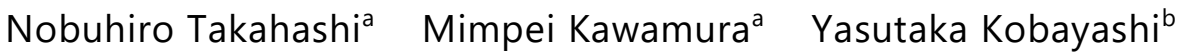 \\ aDepartment of Rehabilitation, Fukui College of Health Sciences, Fukui City, Japan; \\ ${ }^{b}$ Department of Rehabilitation Medicine, Fukui General Hospital, Fukui City, Japan
}

\section{Keywords}

Marchiafava-Bignami disease · Nonalcoholic disease · Gastric cancer · Malnutrition · Callosal disconnection · Agraphia

\begin{abstract}
We report a 68-year-old right-handed female who was admitted to our hospital complaining chiefly of incontinence and decreased activity. Her brain images showed characteristics of Marchiafava-Bignami disease, such as symmetrical abnormal signals localized in the corpus callosum. The patient had no drinking habits. Her past medical history included total gastric resection to treat gastric cancer. On hospital admission she was markedly underweight. This appeared to be a rare case of Marchiafava-Bignami disease not attributable to heavy drinking and occurring in a state of malnutrition. Evaluation of callosal dissociation symptoms produced findings indicative of such symptoms. She showed a marked difficulty in writing dictated single words and short sentences in Japanese alphabetic characters, especially with her left hand. In contrast, writing dictated words in Chinese characters (also used in written Japanese) was affected in both hands, with different types of dysgraphia seen in the right and left hands. The
\end{abstract}




\section{Case Reports in Neurology}

Case Rep Neurol 2018;10:232-241

DOI: $10.1159 / 000492528$

(C) 2018 The Author(s). Published by S. Karger AG, Basel www.karger.com/crn

Takahashi et al.: Agraphia in Marchiafava-Bignami Disease

agraphia in the left hand seen in this patient appears to have occurred as a result of the language faculty of the left hemisphere failing to be transmitted to the right brain, while agraphia in the right hand may have occurred as a result of spatial processing information in the right hemisphere failing to be transmitted to the left hemisphere.

(C) 2018 The Author(s)

Published by S. Karger AG, Basel

\section{Introduction}

Marchiafava-Bignami disease, which can develop in heavy drinkers, is a rare condition that causes demyelination and necrosis, mostly of the corpus callosum (CC) [1]. Although it is generally thought to be caused by chronic overconsumption of alcohol and the resultant nutritional disorders, cases of Marchiafava-Bignami disease occurring in individuals with no history of drinking have also been reported, although extremely rarely. It is therefore assumed that the disease can be induced by nutritional disorder alone [2]. The patient we encountered had developed this disease despite having no drinking habits. Since few reports of nonalcoholic Marchiafava-Bignami disease exist, we report this case here.

If the CC becomes damaged because of Marchiafava-Bignami disease, fiber-mediated exchanges can no longer be carried out between the two cerebral hemispheres. Callosal disconnection symptoms may therefore appear, reflecting the site of the CC damage. Ordinarily, with right-handed people, the left hemisphere is predominantly involved in language and behaviors/actions, while the right hemisphere functions predominantly in visuospatial perception. Because of this asymmetry, if the two cerebral hemispheres are separated, callosal disconnection symptoms appear [3]. The patient we encountered showed no callosal disconnection symptoms, evaluated as activities of daily living, during her hospitalization. She also made no subjective complaints. Nevertheless, her evaluation revealed callosal disconnection symptoms. Her writing of Chinese characters, in particular, showed agraphia with different characteristics in the two hands. Ordinarily, when agraphia develops in connection with callosal disconnection syndrome, it occurs only in the left hand. This predilection explains why few, if any, reports of agraphia occurring in both hands exist [4].

\section{Case Description}

The patient was a 68-year-old right-handed female. She had become ill around 3 days before visiting our hospital. She had gradually become unable to eat and suffered incontinence. She had articulation difficulty and a decreased activity level. She sought medical attention and was admitted to our hospital. Head magnetic resonance imaging (MRI) (Fig. 1) performed on the day of admission revealed bilaterally symmetrical high-intensity areas on T2-weighted and diffusion-weighted imaging (DWI) in the genu, stem, and splenium of the CC. The apparent diffusion coefficient (ADC) values were low. These high-intensity areas were localized to the inner layer of the CC. A wide-ranging but faint high-intensity diffusion-weighted signal was also present in the frontal lobe white matter. However, since the ADC value of the site was not low, vasogenic edema was suspected. No abnormalities were seen on magnetic resonance angiography. The patient had undergone total gastric resection 18 years previously to treat 


\section{Case Reports in Neurology}

Case Rep Neurol 2018;10:232-241

DOI: $10.1159 / 000492528$

(C) 2018 The Author(s). Published by S. Karger AG, Base www.karger.com/crn

Takahashi et al.: Agraphia in Marchiafava-Bignami Disease

gastric cancer. On admission, she was $140 \mathrm{~cm}$ tall and weighed $23.5 \mathrm{~kg}$, showing that she was clearly underweight. Her blood pressure was $144 / 82 \mathrm{~mm} \mathrm{Hg}$, pulse $55 / \mathrm{min}$, body temperature $35.5^{\circ} \mathrm{C}$, and $\mathrm{SpO}_{2} 94 \%$. She showed disturbance of orientation, as revealed by a Glasgow Coma Scale score of E4 V4 M6. She was able to raise both arms, move her legs, and perform facial movements when instructed, showing no clear motor paralysis. Marchiafava-Bignami disease was diagnosed based on the above clinical course and imaging findings. We immediately provided an intravenous infusion to correct her hydration level and administered vitamins.

On the 16th day after admission, the patient was transferred to our hospital's convalescence ward where she underwent neuropsychological tests and rehabilitation. By this time, her orientation disturbance had disappeared and she was able to converse smoothly. She required no assistance with activities of daily living inside the hospital. During her hospital stay, she showed no clear callosal dissociation symptoms and made no subjective complaints.

\section{Neuropsychological Findings}

The results of a Wechsler Adult Intelligence Scale, 3rd edition [5] evaluation performed between the 11th and 15th day of hospital stay showed verbal IQ of 57, performance IQ of 52, full-scale IQ of 51, verbal comprehension of 54, perceptual organization of 55, working memory of 54, and processing speed of 54, indicating an overall reduction in intellectual function. A Clinical Assessment for Attention [6] performed between the 10th and 12th day of hospital stay showed the patient's scores in all subtests to be sharply below the cutoff points. A Wechsler Memory Scale-Revised [7] test performed between the 17th and 21st day of hospital stay showed verbal memory of 67 , visual memory of $<50$, general memory of $<50$, attention/ concentration of 59 , and delayed recall of $<50$, indicating a deterioration of memory function.

\section{Assessment of Callosal Dissociation Symptoms}

On the 17th day of hospital stay, the patient's bidextrous tactile naming capabilities were tested. We employed the Visual Perception Test for Agnosia (VPTA) [8] to test the naming of various objects, with the patient made to wear an eye mask and close both eyes. Next, a visual naming (designation) test was performed, which confirmed that the patient was able to identify all the objects by sight. The number of correct answers in the tactile naming test was $6 / 8$ for the right hand and 3/8 for the left one (Table 1).

On the 28th day of hospital stay, reading-aloud and naming tasks were performed for both visual fields. In the reading-aloud task, different letters and characters were displayed on a computer screen for $200 \mathrm{~ms}$ in the right and left visual fields; in the naming task, different line drawings were similarly displayed. The patient was instructed to read aloud the letters shown on the right and left sides of the screen and name the line drawings while fixing her gaze on the " + " mark displayed in the center of the screen. One simple Chinese character was displayed. For the line drawings, words that appeared frequently in the Noun Expression Test, a subtest of the Test of Lexical Processing in Aphasia [9], were used. The numbers of correct answers the patient gave for the single Chinese character were $9 / 30$ and $11 / 30$ for the right and left visual field, respectively. The numbers of correct answers for one Japanese alphabetic character were $15 / 30$ and $18 / 30$, respectively. The numbers of correct answers when naming the line drawings were $6 / 20$ and $3 / 20$, respectively. In these naming and reading-aloud tasks, the patient made frequent mistakes, or gave no responses, for both visual fields. 


\section{Case Reports in Neurology}

Case Rep Neurol 2018;10:232-241

DOI: $10.1159 / 000492528$

(C) 2018 The Author(s). Published by S. Karger AG, Base www.karger.com/crn

Takahashi et al.: Agraphia in Marchiafava-Bignami Disease

On the 17th day of hospital stay, actions made by each hand were assessed. To this end, we implemented Subtest VII of the Japanese version of the Western Aphasia Battery [10], namely "Actions: Upper limbs" and "Use of tools." The patient was able to carry out all the actions with either hand without making any mistakes.

On the 17th day of hospital stay, dictation writing using both hands was assessed. The following tests were selected from the subtests in the Standard Language Test of Aphasia [11]: a single Chinese character, a single Japanese alphabetic character, and a short sentence. The number of correct answers the patient gave in the dictation of a single Chinese character was $1 / 5$ for both hands. The error she made in writing dictated Chinese characters with the left hand was clearly attributable to paragraphia; with the right hand, the patient copied the same erroneous characters that she had written with her left hand (Fig. 2a). The numbers of correct answers the patient gave in the dictation writing of short sentences were $4 / 5$ and $1 / 5$ for the right and left hands, respectively (Fig. 2b).

On the 17th day of hospital stay, tasks included in the VPTA [8] such as line cancellation, line bisection, and picture drawing were performed for both hands. The patient was able to complete the line cancellation task without any errors with either hand. However, the scores for the line bisection task were 4/6 points for the right hand (deviation to the left: 2 points; deviation to the right: 2 points) and $1 / 6$ points for the left hand (deviation to the left: 1 point; deviation to the right: 0 points). In this assessment, higher scores indicate more errors. In the clock face drawing task, left unilateral spatial neglect was observed for the right hand (Fig. 3).

\section{Discussion}

Marchiafava-Bignami disease manifests in the pathological findings of demyelination and necrosis, mainly of the CC, caused by malnutrition due to overconsumption of alcohol. Nonalcoholic Marchiafava-Bignami disease has been reported, although extremely rarely, and is assumed to be induced by nutritional disorder alone [2]. The patient in our study had undergone total gastric resection to treat gastric cancer and was extremely underweight. As a result, her nutritional state on hospital admission was poor. Her head MRI revealed bilaterally symmetrical high-intensity areas on T2-weighted imaging and DWI localized in the genu, anterior stem, and splenium of the CC. These high-intensity areas were localized at the inner layer of the $\mathrm{CC}$. The cerebral imaging findings of Marchiafava-Bignami disease were reported to show bilateral asymmetrical high-intensity signals on T2-weighted images and DWI [12]. The lesions appeared to be localized to the middle layer of the CC, while the upper and lower layers appeared to have escaped significant damage (the "sandwich sign") [13]. Our patient's imaging findings were consistent with these reports.

If the cerebral hemispheres become functionally separated because of CC damage, symptoms of callosal dissociation may appear. In most right-handed individuals, the left hemisphere governs language and behaviors/actions. Following CC damage, information entering from the left visual field or hand reaches the right hemisphere, but is sometimes not transmitted to the left hemisphere, preventing language processing. In addition, linguistic and action/ behavior-related information, mainly governed by the left hemisphere, is not output to the right hemisphere controlling left-hand movements, which results in impairments in both linguistic responses and left-hand actions. The visuospatial analysis and composition functions 


\section{Case Reports in Neurology}

Case Rep Neurol 2018;10:232-241

DOI: $10.1159 / 000492528$

(C) 2018 The Author(s). Published by S. Karger AG, Basel www.karger.com/crn

Takahashi et al.: Agraphia in Marchiafava-Bignami Disease

of right-handed individuals are mainly governed by the right hemisphere. If the CC is damaged, information related to these functions is not transmitted to the left hemisphere, which governs right-hand movements. Therefore, if work is performed by the right hand under such circumstances, visuospatial problems, such as unilateral spatial neglect, will be evident.

Assessment of the patient's callosal dissociation symptoms revealed left-hand tactile naming disorder, bilateral visual naming and reading-aloud disorders, bidextrous agraphia, and left unilateral spatial neglect in the right hand. Table 2 shows the symptoms found in our patients and the symptoms seen in typical cases of callosal dissociation. Left-hand tactile naming disorder may be related to injury to the CC stem [14]. Our patient's site of damage also matched her impairments: she had greater difficulty with tactile naming with her left than with her right hand, which may be attributable to callosal dissociation. Naming disorder and dyslexia in the left visual field may be related to injury to the CC splenium [14]. Our patient's brain images clearly showed damage in the splenium of the CC, which may interfere with the exchange of information between the hemispheres. Our patient, however, made frequent errors in naming and reading aloud, or gave no response, in both visual fields, showing no clear left-right differences. She showed reduced intellectual and attention functions; hence, the inability to respond to brief ( $200 \mathrm{~ms}$ ) stimulation is likely to have been the major reason for her difficulty in naming and reading aloud stimuli presented to both visual fields.

Left-hand agraphia may be related to damage in the anterior trunk of the CC, particularly its central portion [14]. Our patient's head MRI showed abnormal intensity signals in these sites, suggesting that nerve fibers of the $\mathrm{CC}$ had been damaged. In the dictation writing of single alphabetic characters and short sentences, our patient experienced a marked difficulty in using her left hand. In contrast, in writing single Chinese characters, she experienced difficulty with both hands. Agraphia caused by callosal dissociation is usually seen only in the left hand. The mechanism of left-hand agraphia may involve information needed for writing characters, which is evoked in the left hemisphere, not being transmitted to the right hemisphere, thus impeding writing letters with the left hand [15]. This mechanism can explain the left-hand agraphia seen in our patient. However, the patient also had difficulty writing Chinese characters with her right hand. A general inability to write Chinese characters because of the overall reduction in intellectual function cannot explain the left-right laterality of the patient's Chinese character writing. When writing Chinese characters, she was clearly suffering paraphasia when she used her left hand; when she used her right hand, however, she wrote the same characters she had written on the left-hand side, a type of error seen in left unilateral spatial neglect. A case has been reported of a patient who, after suffering CC infarction, manifested different types of agraphia in the right and left hands. That particular patient, however, was left-handed [4], whereas our patient is right-handed. Her responses in the dictation task showed agraphia in the left hand, which normally occurs after CC injury, and showed dysgraphia with different characteristics between the two hands only when writing Chinese characters. Chinese characters have more strokes and more complicated character forms than Japanese alphabetic letters. Therefore, when writing Chinese characters, one must conduct spatial analysis beforehand more thoroughly than when writing alphabetic letters. The difficulty our patient experienced in writing Chinese characters with her right hand may have been caused by errors due to left unilateral spatial neglect while executing the movement of writing letters, since spatial information, which is mainly governed by the right hemisphere, had not been transmitted to the left hemisphere. In the line bisection tests and picture drawing tasks, 
visuospatial processing deficits, such as left unilateral spatial neglect, manifested more strongly in the right than in the left hand. This asymmetry also suggests that right-hand-associated unilateral spatial neglect was likely involved in the error seen in our patient's dictation writing of single Chinese characters with her right hand.

\section{Statement of Ethics}

The authors have no ethical conflicts to disclose.

\section{Disclosure Statement}

The authors declare that they have no conflicts of interest to disclose.

\section{References}

1 Brion S. Marchiafava-Bignami disease. In: Vinken PJ, Bruyn GW, editors. Handbook of clinical Neurology. Amsterdam: North Holland; 1977. pp. 317-29.

2 Tao H, Kitagawa N, Kako Y, Yamanaka H, Ito K, Denda K, et al. A case of anorexia nervosa with MarchiafavaBignami Disease that responded to high-dose intravenous corticosteroid administration. Psychiatry Res. 2007 Nov;156(2):181-4.

3 Ihori N, Kawamura M. [Corpus callosum and somesthetic transfer]. Brain Nerve. 2014 Apr;66(4):341-50.

4 Furuki H, Kaibai Y, Hara H. A case of cerebral infarction presenting callosal disconnection syndrome with bilateral agraphia. Neuropsychological consideration on the pathologic mechanism of bilateral agraphia. Cognitive Rehabilitation. 2010;15:62-9.

5 Fujita K, Maekawa H, Dairoku K, Yamanaka K. The Japanese version of the Wechsler Adult Intelligence Scale-III. Tokyo: Nihon Bunka Kagakusha; 2007.

6 Japan Society for Higher Brain Dysfunction. Clinical Assessment for Attention. Tokyo: Shinko Igaku Syuppansya; 2008.

7 Sugishita M. The Japanese version of the Wechsler Memory Scale-Revised. Tokyo: Nihon Bunka Kagakusha; 2007.

8 Japan Society for Higher Brain Dysfunction. Visual Perception Test for Agnosia. Tokyo: Shinko Igaku Syuppansya; 2003.

9 Fujita I, Monoi H, Okudaira N, et al. A Test of Lexical Processing in Aphasia. Tokyo: Esco Earl; 2000.

10 Sugishita M. Japanese version of Western Aphasia Battery. Tokyo: Igakushoin; 1986.

11 Japan Society for Higher Brain Dysfunction. Standard Language Test of Aphasia. Tokyo: Shinko Igaku Syuppansya; 2006.

12 Kawamura M, Shiota J, Isono O, Hirayama K. Longitudinal X-ray computed tomography study of a patient with Marchiafava-Bignami disease. Chiba Med. 1990;66:37-43.

13 Hlaihel C, Gonnaud PM, Champin S, Rousset H, Tran-Minh VA, Cotton F. Diffusion-weighted magnetic resonance imaging in Marchiafava-Bignami disease: follow-up studies. Neuroradiology. 2005 Jul;47(7): 520-4.

14 Otsuki M. Neuropsychological impairment following callosal and related lesions. Jpn J Neurosurg. 2009;18(3):179-86.

15 Geschwind N. Disconnexion syndromes in animals and man. I. Brain. 1965 Jun;88(2):237-94. 


\section{Case Reports in Neurology}

www.karger.com/crn

Takahashi et al.: Agraphia in Marchiafava-Bignami Disease

a

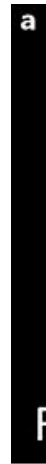

C

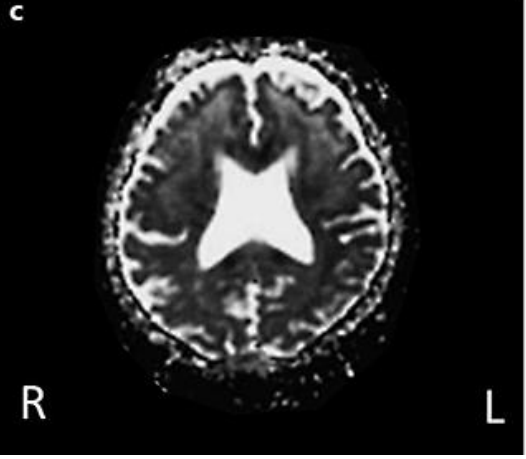

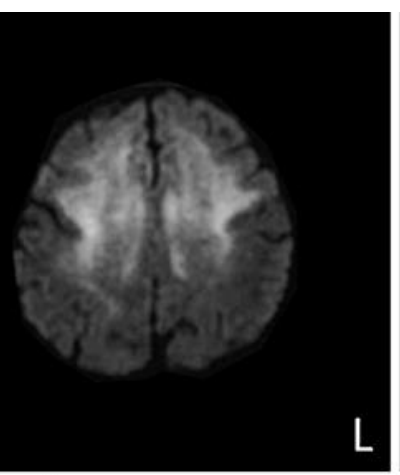

d
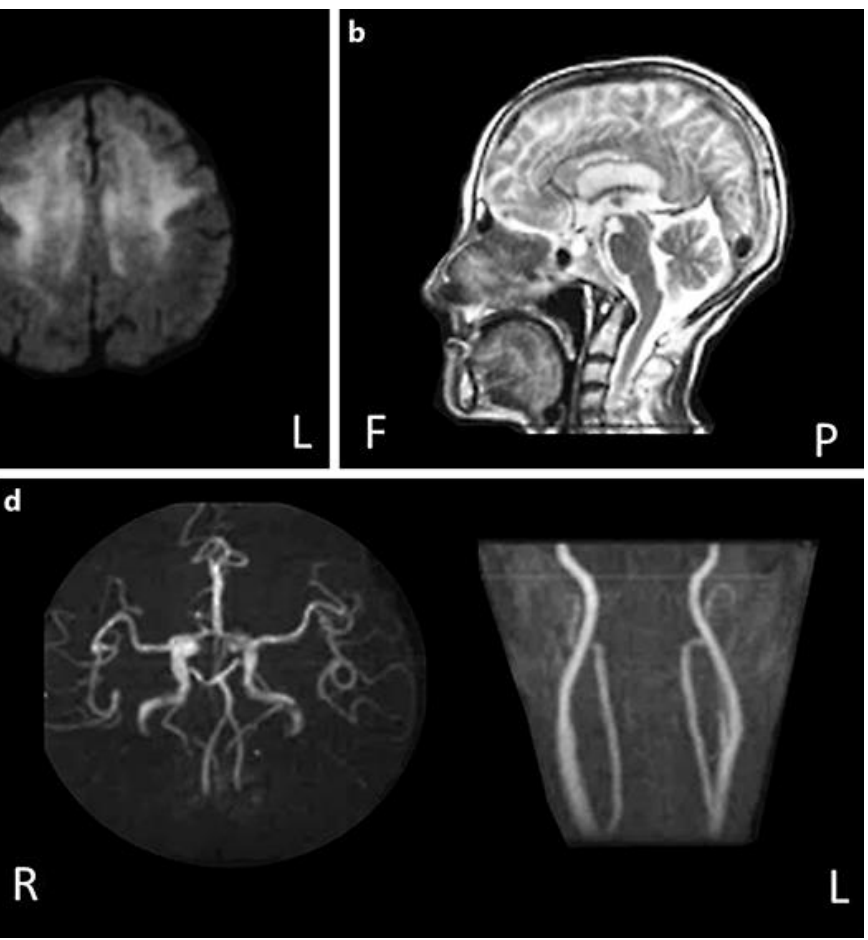

Fig. 1. Head MRI images. a Diffusion-weighted image of a coronal section. Bilaterally symmetrical highintensity signal areas were observed in the genu and splenium of the CC. A wide-ranging faint high-intensity diffusion-weighted signal was seen in the white matter of the frontal lobes. $\mathbf{b}$ T2-weighted image of a sagittal section. Areas of high signal intensity were seen from the anterior stem to the center of the splenium of the CC. These high-intensity areas were localized at the inner layer of the CC. c ADC map of the CC showed a low value. No reduction was seen in the ADC value of the white matter of the frontal lobe. $\mathbf{d}$ No abnormalities were seen in head and neck magnetic resonance angiography. 


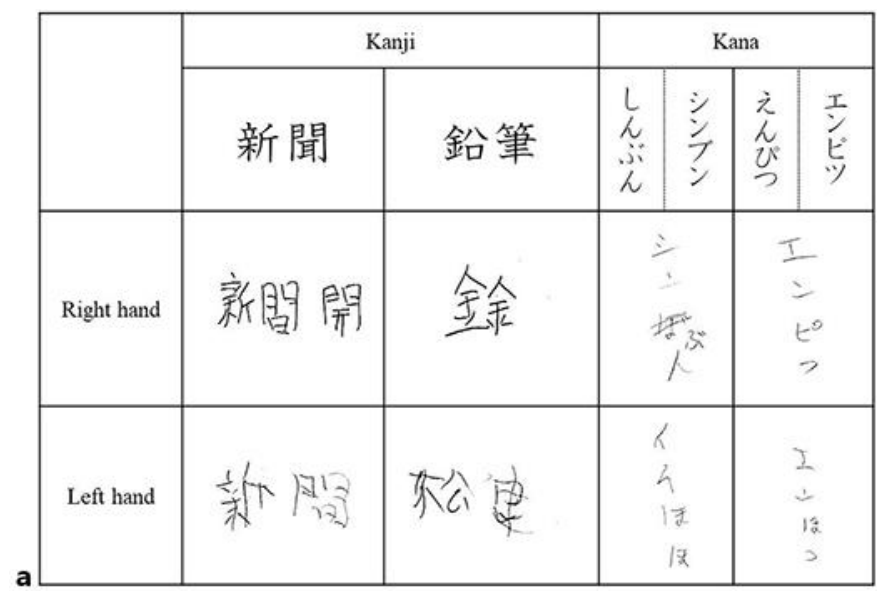

\begin{tabular}{|c|c|c|}
\hline & ぼうがとばされました & すてっきでひろいました \\
\hline Right hand & ぼうがとばされました & すてきでてろッました \\
\hline Left hand & 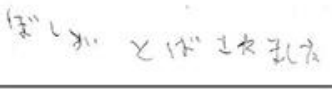 & 人‡2*0 \\
\hline
\end{tabular}

Fig. 2. Samples of characters written by the right and left hands. a Dictation of a single word in Chinese characters and a single word in the Japanese phonetic alphabet. Kanji is Chinese characters, Kana is Japanese phonetic alphabet. b Dictation of short sentences. 


\section{Case Reports in Neurology}
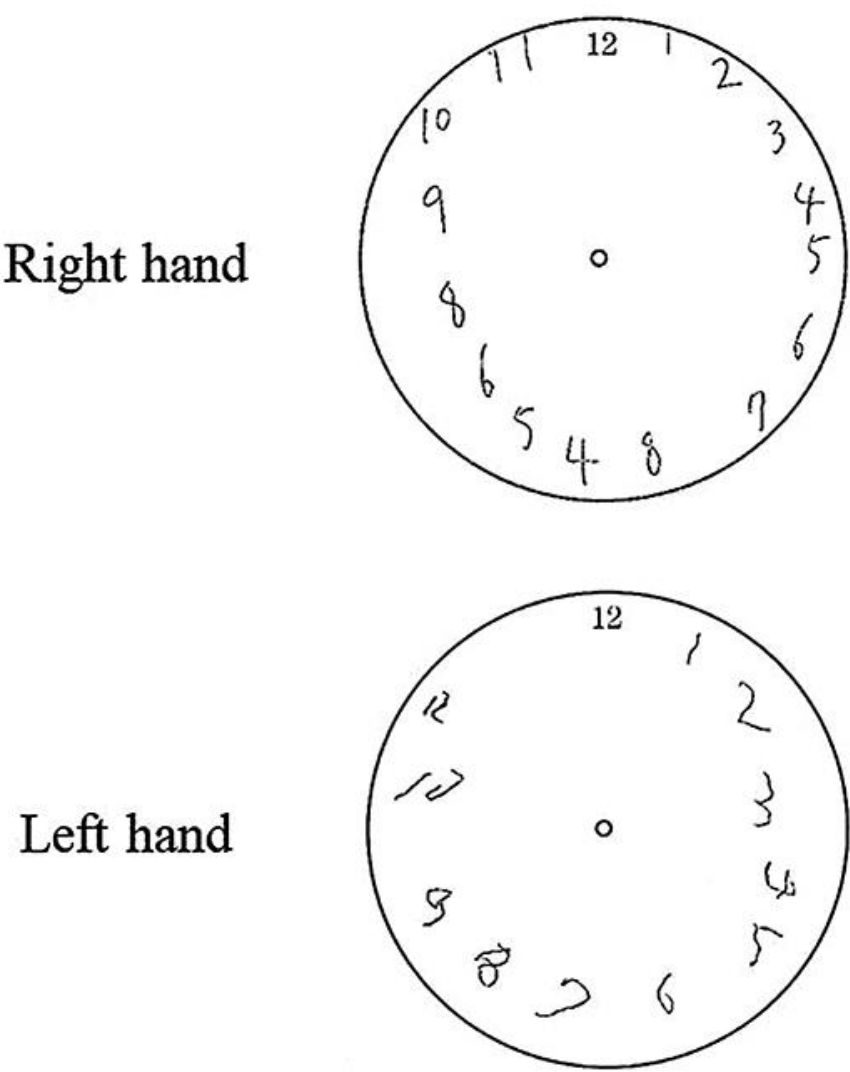

Fig. 3. Drawings of a clock face made using the right and left hands. When the right hand was used, a blank space and duplication of numbers were seen on the left side of the dial, indicating left unilateral spatial neglect. 
Table 1. Responses to the tactile and visual naming tasks using the right and left hands

\begin{tabular}{|c|c|c|c|}
\hline & \multicolumn{2}{|l|}{ Tactile naming task } & \multirow{2}{*}{$\begin{array}{l}\text { Visual naming } \\
\text { task }\end{array}$} \\
\hline & right hand & left hand & \\
\hline Hammer & correct answer & bicycle mirror & correct answer \\
\hline Key & $\begin{array}{l}\text { something placed inside a lunch box } \\
\text { to stick something with }\end{array}$ & something to stick with & correct answer \\
\hline Comb & correct answer & correct answer & correct answer \\
\hline Spoon & correct answer & eyeglass frame & correct answer \\
\hline Pencil & correct answer & correct answer & correct answer \\
\hline Glass cup & correct answer & D.K. & correct answer \\
\hline Candle & jump rope & jump rope & correct answer \\
\hline Ball & correct answer & correct answer & correct answer \\
\hline $\begin{array}{l}\text { Number of } \\
\text { correct answers }\end{array}$ & $6 / 8$ & $3 / 8$ & $8 / 8$ \\
\hline
\end{tabular}

With tactile naming, more difficulty was seen in naming an object when the left hand was used than when the right hand was used. The patient was able to perform all the visual naming tasks.

Table 2. The symptoms found in our patient and the symptoms seen in typical cases of callosal dissociation

\begin{tabular}{lll}
\hline & Our patient & Typical cases \\
\hline Tactile naming disorder & left hand & left hand \\
Visual naming disorder & both visual fields & left visual field \\
Dyslexia & both visual fields & left visual field \\
Agraphia & Japanese phonetic alphabet: left hand & left hand \\
Left unilateral spatial neglect & Chinese characters: both hands & right hand
\end{tabular}

